\title{
Estudio longitudinal de las transiciones a un año entre estados de fragilidad en personas mayores que viven en la comunidad
}

\author{
L. Lorenzo-López, R. López-López, A. Maseda, A. Buján, N. Cibeira, J.C. Millán- \\ Calenti
}

Universidade da Coruña, Grupo de Investigación en Gerontología, Instituto de Investigación Biomédica de A Coruña (INIBIC), Complexo Hospitalario Universitario de A Coruña (CHUAC), SERGAS, A Coruña, España

\begin{abstract}
Objetivos: La fragilidad es un proceso dinámico e individual, es necesaria la exploración en profundidad de su aparición y progresión, dado que es un fuerte predictor de discapacidad y otros procesos adversos en la población mayor. El objetivo fue estudiar la evolución natural de la fragilidad explorando las transiciones entre los estados de fragilidad en el período de un año en una muestra de personas de $65 \mathrm{o}$ más años que viven en la comunidad.
\end{abstract}

Método: De los 749 participantes evaluados al inicio en el marco del proyecto VERISAÚDE, 537 $(71,7 \%)$ fueron re-evaluados a los 12 meses de seguimiento. La fragilidad se diagnosticó mediante los cinco criterios del fenotipo físico de Fried: pérdida involuntaria reciente de peso, cansancio autoinformado, baja actividad física, debilidad muscular y reducción de la velocidad de la marcha. Los participantes fueron clasificados como: frágiles, si satisfacían 3 o más de estos criterios; pre-frágiles, si cumplían 1 o 2 , y robustos, si no presentaban ninguno. Se calcularon los índices de transición (estabilidad, empeoramiento, mejoría) entre los estados de fragilidad.

Resultados: La mayoría de los participantes se mantuvieron en su estado de fragilidad inicial $(57,1 \%$ robustos, $83,4 \%$ pre-frágiles, $66,7 \%$ frágiles). El $42,9 \%$ de los mayores robustos al inicio empeoraron al estado de pre-fragilidad, y el 7,9\% de pre-frágiles empeoraron a fragilidad. Es importante destacar que el $33,3 \%$ de los sujetos frágiles mejoraron hacia la pre-fragilidad, y el 8,7\% de pre-frágiles revirtieron hacia la robustez. Las mujeres robustas mostraron una tendencia a empeorar hacia la pre-fragilidad en mayor medida que los hombres, y la mortalidad fue mayor entre los mayores clasificados como frágiles en la valoración inicial.

Conclusiones: Nuestros resultados confirman la naturaleza dinámica y bidireccional del síndrome de fragilidad y lanzan un mensaje optimista, demostrando que no solo los sujetos pre-frágiles (etapa preclínica de la fragilidad) sino también los frágiles presentan la capacidad de revertir o mejorar, lo que puede tener importantes repercusiones clínicas a la hora de elaborar programas de intervención preventivos de fragilidad.

Este trabajo ha sido financiado por la Xunta de Galicia (ED431C2017/49 y Red FrailNet IN607C 2016/08). 